\title{
Whole-body thermal therapy as adjuvant therapy to radiation in a dog with metastasized anal sac adenocarcinoma
}

\author{
Algehele warmtebehandeling als adjuvanttherapie bij radiotherapie bij een hond \\ met uitgezaaid anaalzakadenocarcinoom
}

${ }^{1}$ S. Janssen, ${ }^{2}$ B. Wylleman, ${ }^{3}$ K. Kromhout, ${ }^{4}$ J. Benoit, ${ }^{1}$ S. Marynissen, ${ }^{1}$ I. Van de Maele, ${ }^{1,5}$ H. de Rooster

${ }^{1}$ Small Animal Department, Faculty of Veterinary Medicine, Ghent University, Salisburylaan 133, B-9820 Merelbeke, Belgium

${ }^{2}$ ElmediX NV, Esperantolaan 4, B-3001 Leuven, Belgium

${ }^{3}$ Department of Medical imaging of Domestic Animals and Orthopedics of Small Animals,

Faculty of Veterinary Medicine, Ghent University, Salisburylaan 133, B-9820 Merelbeke, Belgium

${ }^{4}$ Oncovet Veterinary Cancer Center, Radiation Oncology, Avenue Paul Langevin, 59650 Villeneuve-d'Ascq, France

${ }^{5}$ Cancer Research Institute Ghent (CRIG), Medical Research Building, University Hospital Ghent, Corneel Heymanslaan 10, B-9000 Ghent, Belgium

\section{Simone.Janssen@UGent.be}

\section{$\Lambda_{\text {bstract }}$}

An eleven-year-old Galgo Espagnol was diagnosed with metastasized anal sac adenocarcinoma. The patient was enrolled into a clinical trial and underwent three "whole-body thermal therapy" (WBTT) sessions combined with four hypofractionated radiotherapy sessions during a ten-weeks' time period. The medical device and corresponding treatment protocol were designed by ElmediX (ElmediX NV, Belgium). Air was injected at high speed in a treatment chamber and automatically regulated to reach and maintain a body temperature of $41.5^{\circ} \mathrm{C}$ for eight hours. Thermometry was ensured by temperature sensors placed in and on the patient. During four radiotherapy sessions, an external beam delivered hypofractionated doses of $6 \mathrm{~Gy}$ on both the primary tumor and the metastatic lymph nodes. Clinical monitoring and assessment of quality of life confirmed that the WBTT sessions were well tolerated. Although burn wounds at pressure points occurred, prolonged severe adverse effects were not observed. Furthermore, the disease progression was deemed slower than the expected progression based on the literature.

\section{SAMENVATTING}

Bij een elf jaar oude Spaanse galgo werd een uitgezaaid anaalzakadenocarcinoom gediagnosticeerd. De patiënt werd opgenomen in een klinische studie van drie algehele warmtebehandelingsessies gecombineerd met vier hypofractionaire radiotherapiesessies verspreid over tien weken. Het medische toestel en het behandelingsprotocol werden ontwikkeld door ElmediX (ElmediX NV, België). Lucht werd onder hoge snelheid in het behandelingstoestel gebracht en automatisch aangepast om acht uur lang een lichaamstemperatuur van $41,5^{\circ} \mathrm{C}$ te garanderen. De temperatuur werd gemeten met temperatuursensoren die in en op de patiënt geplaatst werden. Tijdens de vier radiotherapiesessies werden de primaire tumor en de metastatische lymfeknopen, met behulp van een externe stralingsbron, behandeld met hypogefractioneerde doseringen van 6Gy. Klinische monitoring en beoordeling van de levenskwaliteit bevestigden dat de algehele warmtebehandelingsessies goed getolereerd werden. Brandwonden op drukpunten werden waargenomen, maar er werden geen langdurige ernstige bijwerkingen vastgesteld. Daarnaast leek de progressie van de ziekte langzamer dan de verwachte progressie beschreven in de literatuur. 


\section{CASE HISTORY}

An eleven-year-old, female, spayed, Galgo Espagnol was presented to the Veterinary Hospital of the Faculty of Veterinary Medicine (Ghent University, Belgium), to be enrolled as a presumed healthy dog in a doctoral project studying early detection of kidney disease in senior dogs. The physical examination revealed moderate gingivostomatitis, regional enlargement of the submandibular and prescapular lymph nodes and moderate, stress-related, hypertension (Doppler method: $180.0 \mathrm{mmHg}$; High definition oscillometry: $144.8 \mathrm{mmHg}$ ). On hematology, neutropenia was noticed, which was presumed to be breed-associated $\left(2.59 \times 10^{9} . \mathrm{L}^{-1}\right.$ reference interval, 2.95-11.64 $\mathrm{x} 10^{9} . \mathrm{L}^{-1}$ ) and urinalysis revealed isosthenuria (USG 1.019) with pronounced renal proteinuria (UPC 2.6).

Thoracic radiographs and an abdominal ultrasound were scheduled to identify the cause of the proteinuria. The radiographs revealed no abnormalities. The abdominal ultrasound showed a mildly distended urinary bladder with anechoic fluid, and normally shaped kidneys with a normal cortico-medullary distinction, and no distention of the pelvis. Both adrenal glands were relatively large but retained their normal shape and echogenicity. The right medial iliac and right internal iliac lymph node were markedly enlarged (approximately $30 \mathrm{~mm}$ ), rounded, and the parenchyma had a heterogeneous echogenicity. Since this finding was suspicious for either inflammation or neoplasia in the draining area, the perineal area was also screened by ultrasonography. Both anal sacs were filled with echogenic fluid but at the right side, an ovoid hyperechoic, vascularized, nodule arose from the ventromedial wall. Fine-needle aspirations of the anal sac nodule and of the right medial and right internal iliac lymph nodes were obtained under ultrasound guidance. Cytology revealed clusters of malignant epithelial cells embedded in cytoplasm with poorly delineated cell margins and the presence of various criteria for malignancy, such as anisocytosis, anisokaryosis, multiple nucleoli and coarse chromatin in the primary tumor as well as in the lymph nodes. The diagnosis of metastatic anal sac apocrine gland adenocarcinoma (ASAGA) was made.

To assess the extent of the metastatic disease, a thoraco-abdominal computed tomography (CT) scan was performed. The patient was intravenously (IV) premedicated with butorphanol (Dolorex $\AA$; 0.20 mg.kg-1; Intervet International, Brussel, Belgium) and midazolam (Midazolam Mylan ${ }^{\circledR}$; $0.38 \mathrm{mg} \cdot \mathrm{kg}^{-1}$; Cenexi; Fontenay-sous-Bois, France). General anesthesia was induced with propofol IV to effect (Propovet Multidose ${ }^{\circledR}$; $4.90 \mathrm{mg} . \mathrm{kg}^{-1}$; Zoetis; Louvain-laNeuve, Belgium). Maintenance of general anesthesia was obtained by inhalation of isoflurane (Isoflutek ${ }^{\circledR}$; Laboratorios Karizoo; Barcelona, Spain). The CT scan confirmed the nodule in the right anal sac; it was hyperattenuating and ovoid-shaped. The right medial iliac $(35.6 \times 26.4 \times 22.5 \mathrm{~mm})$ and the right internal iliac lymph node $(38.3 \times 24.7 \times 29.6 \mathrm{~mm})$ showed a heterogenous post-contrast attenuation with hypovascular hilar areas, indicative of malignant infiltration (Cui et al., 2013). Hyperattenuating micronodules were visible in the caudal aspect of both lung lobes and were considered to most likely represent pulmonary osteomatosis. Based on these images, there were no indications for distant metastases. A blood sample was taken for measurement of ionized calcium, of which the value was within the normal range (2.41 mmol.L $\mathrm{L}^{-1}$; within the reference interval of 1.98-3.00 mmol. $\left.L^{-1}\right)$.

Proposed options were surgery, in combination with radiotherapy or chemotherapy, or a palliative medical treatment approach with a tyrosine kinase inhibitor or non-steroidal anti-inflammatory drugs. Surgery was considered too complex and invasive due to the extent of abdominal metastases and would require adjuvant therapy to prevent further spread of the metastatic disease. Furthermore, chemotherapy and radiotherapy were declined by the owners because they were worried about the possible side effects in their apparently healthy dog. Since the owners were not keen on any of the traditional curative-intent treatment modalities, an ethically approved experimental clinical trial, involving whole-body thermal therapy (WBTT), was discussed with them as a potential alternative. Prior to the actual enrollment, a complete physical examination, an echocardiography, an electrocardiogram and a quality-of-life (QoL) assessment were performed. Blood samples were taken for hematology, biochemistry and coagulation times. The patient fulfilled all inclusion criteria. The owners received in-depth information about the experimental treatment protocols, including the possibility and added value of low-dose adjuvant radiotherapy after WBTT, which was believed to limit the seriousness of the side effects from conventional treatment strategies. The owners were well informed of all steps and risks and agreed with the full protocol, consisting of three WBTT sessions and four sessions of radiotherapy with a dose of $6 \mathrm{~Gy}$, of which three immediately following a WBTT session. Written informed consent was signed.

The clinical study took place at the Oncovet Veterinary Cancer Center (Villeneuve d'Ascq, France) with the cooperation of Oncovet Clinical Research (OCR). The protocol was approved by OCR's ethical committee. A schematic overview of the WBTT sessions and follow-up days is shown in Figure 1.

The patient was hospitalized the day before the actual treatment (D-1) to guarantee a perfect hydration status at the start of the WBTT. A complete physical examination was repeated, and hematology, serum biochemistry, electrolytes and coagulation profiles were monitored for safety measures prior, during and after each treatment.

A pre-established anesthetic protocol was used for all WBTTs after a peripheral catheter had been placed 


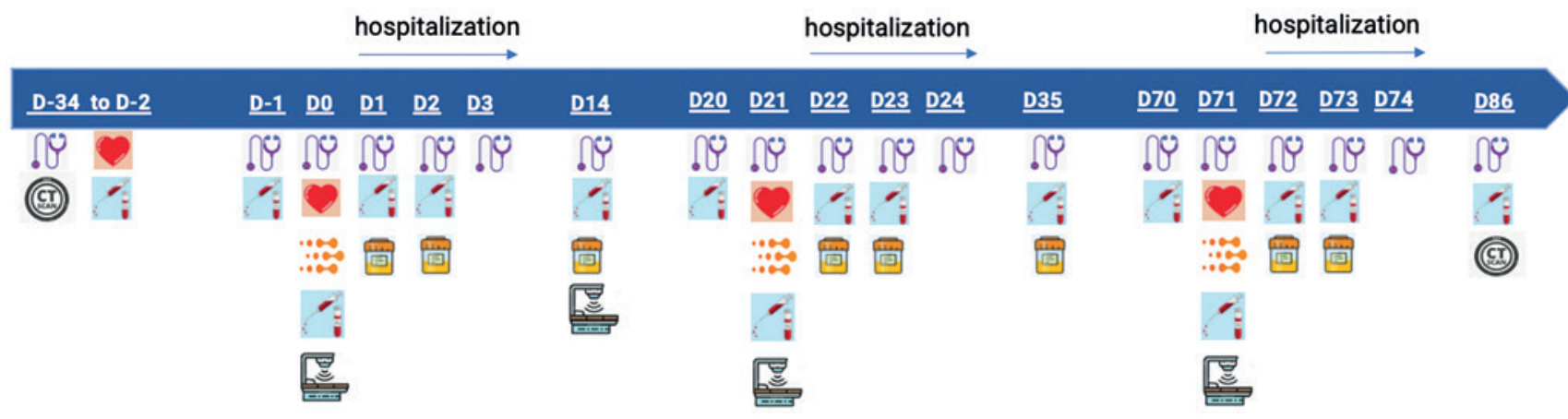

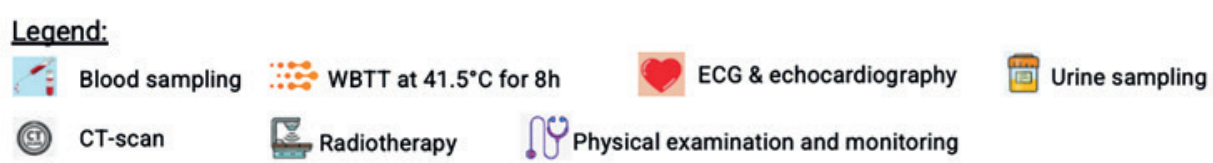

Figure 1. A schematic overview on the whole-body thermal therapy (WBTT) sessions, sampling, and follow-up days. $D=$ day; D-1 = hospitalization day prior to the actual treatment; D0 $=1^{\text {st }}$ WBTT treatment; D1-D3 $=$ hospitalization days after treatment; D14, D35 and D86 are the follow-up dates. Permission granted, an edited version of the original timeline created by EImediX NV (2020).

in a cephalic vein: 15 minutes before anesthesia, the patient was premedicated with morphine IV (Morphine Chlorhydrate Cooper® Sanofi; $0.2 \mathrm{mg} \cdot \mathrm{kg}^{-1}$; Paris, France) and the administration of morphine was repeated every three hours. General anesthesia was induced IV with a combination of propofol $\left(2 \mathrm{mg} \cdot \mathrm{kg}^{-1}\right)$ and ketamine (Ketamidor ${ }^{\circledR} ; 1 \mathrm{mg} \mathrm{kg}^{-1}$; Richter Pharma AG; Wels, Austria). The patient was intubated, and the cuff was inflated but deflated and re-inflated every four hours. A pulse oximeter and electrocardiogram were installed.

During the induction, temperature flow sensors and temperature sensors were calibrated at $41.5^{\circ} \mathrm{C}$ to ensure a reliable measurement of body temperature during treatment. The sensors were thereafter disinfected with alcohol and placed on and in the patient. The main steering temperature sensor was placed about 3-4 $\mathrm{cm}$ deep in the left lateral liver lobule under ultrasound-guidance with an AniCath L/A 16g, $133 \mathrm{~mm}$ catheter. This specific site was chosen due to its easy accessibility and to ensure avoidance of other organs, namely the spleen. The other sensors were placed in the rectum, close to the tumor in the right anal sac, on the skin at the level of the liver, in the treatment cabinet and in the treatment room.

General anesthesia was maintained with $2 \%$ volatile isoflurane in diluted oxygen. Fluid therapy (Ringer Lactate ${ }^{\circledR} ; 10 \mathrm{ml} \cdot \mathrm{kg}^{-1} \cdot \mathrm{h}^{-1} ; \mathrm{B}$. Braun Melsungen AG; Melsungen, Germany) was provided. An arterial catheter was placed in a dorsal pedal artery. A urinary catheter connected to a collection bag was placed to monitor urine output. Furthermore, eye ointment was applied to the corneal surface and mucous membranes were regularly moistened. As soon as the patient was installed in the treatment cabinet, a constant rate infusion (CRI) of midazolam $\left(0.2 \mathrm{mg} \cdot \mathrm{kg}^{-1} \cdot \mathrm{h}^{-1}\right)$ was ad- ministered. Mechanical ventilation was instituted at a tidal volume of $10-12 \mathrm{ml} . \mathrm{kg}^{-1}$ and a respiratory rate of 12 per minute. The positive-inspiratory-pressure (PIP) was set for no more than $20 \mathrm{~cm}_{2} \mathrm{O}$ according to the expiratory (ET) $\mathrm{CO}_{2}$ values of $40-45 \mathrm{mmHg}$. No positive-end-expiratory-pressure (PEEP) was used. On the abdomen, a heat flux sensor was positioned to monitor the provided and extracted heat during treatment (Figure 2). For rectal measurement of the body temperature, a standard temperature hospital probe was inserted into the rectum and connected to the sensor in the rectum. The treatment was then initiated.

The HyperTherm treatment cabinet, in which the patient was installed, consists of four units: (1) the treatment chamber; (2) the sensing unit; (3) the regu-

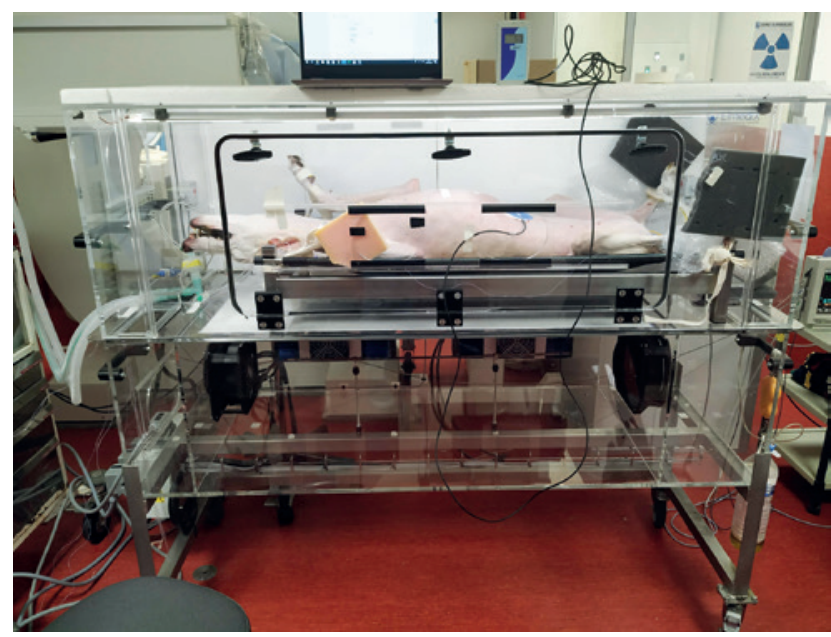

Figure 2. The patient was placed into the treatment cabinet and connected to all relevant equipment. A heat flux sensor on the abdomen monitored the provided and extracted heat during treatment. 
lation unit; and (4) the data logging unit. Air is injected at high speed in a treatment chamber to regulate the patient's temperature, which is being continuously measured by an invasive sensor in the liver. The temperature sensors deliver the data into the regulation unit, an accurate proportional-integral-derivative controller present within the treatment cabinet, which automatically regulates the circulating air temperature based on the data collected from all temperature sensors. During the heating phase, the air temperature is around $41.5^{\circ} \mathrm{C}$ in order to heat up the patient; during the plateau phase, it is much lower, in order to maintain the patient's core temperature around the setpoint of $41.5^{\circ} \mathrm{C}$ while metabolic heat production rises.

Heat was delivered through circulating warm air. An increase in body temperature took place at a rate of $2^{\circ} \mathrm{C} /$ hour until the designed treatment temperature of $41.5^{\circ} \mathrm{C}$ was reached and read-out on the temperature sensor in the liver. This temperature was then maintained for eight hours. The highest temperature measured by the liver sensor in this patient during treatment was $41.53^{\circ} \mathrm{C}$, the maximum cabinet temperature was $41.52^{\circ} \mathrm{C}$ and the highest temperature measured at the level of the tumor during treatment was $41.56^{\circ} \mathrm{C}$.
The length of the WBTT at $41.5^{\circ} \mathrm{C}$ was decided on by ElmediX, based on previous experiments.

Thereafter, the cooling phase was initiated. The treatment cabinet was opened and all sensors were disconnected from the patient. Additionally, the patient was disconnected from the gas anesthesia machine. The patient, still intubated, was thereafter immediately moved from the treatment cabinet to the radiotherapy room where the patient was again connected to the gas anesthesia machine. External beam radiotherapy was used (Elekta Precise ${ }^{\circledR}$; 6MV; Stockholm, Sweden) to apply hypofractionated dose fractions (6Gy every 1-3 weeks for a total dose of 24Gy) at the primary tumor as well as the lymphatic metastases. For an optimal synergistic effect between the two treatment modalities, all three WBTT sessions were immediately followed by three radiotherapy sessions, while still under anesthesia. The one radiotherapy session not following a WBTT session was applied during a follow-up examination. During these radiotherapy sessions, the dog was breathing spontaneously. After the radiotherapy sessions, the patient was brought back to the hospitalization room, where the patient recovered from anesthesia. The patient

Table 1. Changes in hematology and serum biochemistry during each whole-body thermal therapy and at one, two and approximately eleven days after treatment (T24h, T48h and the follow-up days (D14, D35, D86) respectively).

\begin{tabular}{|c|c|c|c|c|c|c|c|c|c|c|c|c|}
\hline & \multicolumn{4}{|c|}{ WBTT session 1} & \multicolumn{4}{|c|}{ WBTT session 2} & \multicolumn{4}{|c|}{ WBTT session 3} \\
\hline & \multirow[t]{2}{*}{ During } & \multicolumn{3}{|c|}{ After } & \multirow[t]{2}{*}{ During } & \multicolumn{3}{|c|}{ After } & \multirow[t]{2}{*}{ During } & \multicolumn{3}{|c|}{ After } \\
\hline & & T24h & T48h & D14 & & T24h & T48h & D35 & & T24h & T48h & D86 \\
\hline WBCs & $\downarrow * * *$ & $\uparrow *$ & $\uparrow *$ & $\downarrow *$ & $\downarrow * * *$ & 个* & $\downarrow *$ & $\downarrow * * *$ & $\downarrow * * *$ & $\uparrow *$ & $\uparrow *$ & $\downarrow * * *$ \\
\hline RBCs & $\downarrow * * *$ & $\uparrow *$ & $\downarrow *$ & $\uparrow * *$ & $\downarrow * * *$ & $\uparrow *$ & $\downarrow *$ & $\uparrow * *$ & $\downarrow * * *$ & $\uparrow *$ & $\uparrow *$ & $\uparrow *$ \\
\hline Reticulocytes & $\downarrow * * *$ & $\uparrow *$ & $\downarrow * * *$ & $\uparrow * *$ & $\downarrow * * *$ & $\uparrow * * *$ & $\downarrow * * *$ & $\uparrow *$ & $\downarrow * * *$ & $\uparrow * * *$ & $\downarrow * * *$ & $\uparrow *$ \\
\hline Hemoglobin & $\downarrow * * *$ & $\uparrow *$ & $\downarrow *$ & $\uparrow *$ & $\downarrow * * *$ & $\uparrow *$ & $\downarrow *$ & $\uparrow *$ & $\downarrow * * *$ & $\uparrow *$ & $\uparrow *$ & $\uparrow *$ \\
\hline Hematocrit & $\downarrow * * *$ & $\uparrow *$ & $\downarrow *$ & $\uparrow *$ & $\downarrow * * *$ & $\uparrow *$ & $\downarrow *$ & $\uparrow *$ & $\downarrow * * *$ & $\uparrow *$ & $\uparrow *$ & $\uparrow *$ \\
\hline Platelets & $\downarrow * * *$ & $\uparrow *$ & $\downarrow *$ & $\uparrow *$ & $\downarrow * * *$ & $\uparrow *$ & $\uparrow *$ & $\uparrow *$ & $\downarrow * * *$ & $\uparrow *$ & $\uparrow *$ & $\uparrow *$ \\
\hline Plateletcrit & $\downarrow * * *$ & $\uparrow *$ & $\downarrow *$ & $\downarrow *$ & $\downarrow *$ & $\uparrow *$ & $\uparrow *$ & $\uparrow * *$ & $\downarrow * * *$ & $\uparrow *$ & $\uparrow *$ & NA \\
\hline Blood pH & $\uparrow * *$ & NA & NA & NA & $\uparrow *$ & NA & NA & NA & $\uparrow * *$ & NA & NA & NA \\
\hline Urea & $\uparrow *$ & $\downarrow * * *$ & $\uparrow *$ & $\downarrow *$ & $\uparrow *$ & $\downarrow * * *$ & $\uparrow *$ & $\downarrow *$ & $\uparrow *$ & $\downarrow * * *$ & $\uparrow *$ & $\downarrow *$ \\
\hline AST & $\uparrow * *$ & $\uparrow \uparrow * *$ & $\downarrow \downarrow * *$ & $\downarrow *$ & $\uparrow * *$ & $\uparrow * *$ & $\downarrow * *$ & $\downarrow * *$ & $\uparrow * *$ & $\uparrow * *$ & $\downarrow * *$ & NA \\
\hline ALT & $\downarrow * *$ & $\uparrow * *$ & $\downarrow * *$ & $\downarrow * *$ & $\downarrow * *$ & $\uparrow * *$ & $\downarrow * *$ & $\uparrow * *$ & $\downarrow * *$ & $\uparrow * *$ & $\uparrow * *$ & $\downarrow * *$ \\
\hline ALKP & $\downarrow *$ & $\uparrow * *$ & $\downarrow * *$ & $\downarrow *$ & $\downarrow *$ & $\uparrow * *$ & $\downarrow * *$ & $\downarrow * *$ & $\downarrow *$ & $\uparrow * *$ & $\uparrow * *$ & $\downarrow * *$ \\
\hline Total Bilirubin & $\downarrow * * *$ & $\uparrow * *$ & $\downarrow *$ & $\downarrow *$ & $\downarrow * * *$ & $\uparrow *$ & $\downarrow *$ & $\downarrow *$ & $\downarrow * * *$ & $\uparrow *$ & $\uparrow *$ & NA \\
\hline Total Protein & $\downarrow * * *$ & $\uparrow *$ & $\uparrow *$ & $\uparrow *$ & $\downarrow * * *$ & $\uparrow *$ & $\uparrow *$ & $\uparrow *$ & $\downarrow * * *$ & $\uparrow * * *$ & $\uparrow *$ & $\downarrow *$ \\
\hline TG & $\downarrow * * *$ & 个* & $\uparrow *$ & $\uparrow * *$ & $\downarrow * * *$ & $\uparrow *$ & $\uparrow *$ & $\uparrow * *$ & $\downarrow * * *$ & $\uparrow *$ & 个* & NA \\
\hline Potassium & $\downarrow *$ & $\downarrow *$ & $\uparrow *$ & $\uparrow *$ & $\downarrow *$ & $\uparrow *$ & $\uparrow *$ & $\uparrow *$ & $\downarrow *$ & $\downarrow *$ & $\uparrow *$ & $\uparrow *$ \\
\hline Sodium & $\uparrow * *$ & $\downarrow *$ & $\downarrow *$ & $\downarrow *$ & $\uparrow *$ & $\uparrow *$ & $\downarrow *$ & $\downarrow *$ & $\uparrow *$ & $\uparrow *$ & $\downarrow *$ & $\downarrow *$ \\
\hline Ionized $\mathrm{Ca}^{2+}$ & $\downarrow * * *$ & $\uparrow * * *$ & $\downarrow * * *$ & $\uparrow * * *$ & $\downarrow * * *$ & $\uparrow * * *$ & $\downarrow * * *$ & $\uparrow * * *$ & $\downarrow * * *$ & $\uparrow *$ & $\downarrow * * *$ & NA \\
\hline CK & $\uparrow \uparrow * *$ & NA & $\uparrow \uparrow * *$ & $\downarrow *$ & $\uparrow * *$ & $\uparrow \uparrow * *$ & $\downarrow * *$ & $\downarrow *$ & $\uparrow * *$ & $\uparrow \uparrow * *$ & $\downarrow * *$ & NA \\
\hline Lactate & $\downarrow *$ & $\downarrow *$ & $\downarrow *$ & $\uparrow * *$ & $\downarrow *$ & $\downarrow *$ & $\downarrow *$ & $\uparrow * *$ & $\downarrow *$ & $\downarrow *$ & $\downarrow *$ & NA \\
\hline Troponine I & $\uparrow * *$ & $\uparrow * *$ & $\downarrow * *$ & $\downarrow *$ & $\uparrow * *$ & $\uparrow * *$ & $\downarrow * *$ & $\downarrow *$ & $\uparrow * *$ & $\uparrow * *$ & $\downarrow * *$ & NA \\
\hline
\end{tabular}

WBCs $=$ white blood cells; RBCs $=$ red blood cells; AST $=$ aspartate amino transferase; ALT = alanine amino transferase; $\mathrm{ALKP}=$ alkaline phosphatase; $\mathrm{TG}=$ triglycerides; $\mathrm{CK}=$ creatinine kinase; $\uparrow=$ increased; $\uparrow \uparrow=$ extremely increased; $\downarrow=$ decreased; $\downarrow \downarrow=$ extremely decreased; $*=$ within reference interval; $* *=$ above reference interval; $* * *=$ below reference interval; $\mathrm{NA}=$ Not available. Due to fluctuations in values during each treatment, the increase or decrease during treatment is based on the average increase or average decrease compared to the value before anesthesia was induced. Each increase or decrease after treatment is in comparison with the previous time stamp. In example, an increase or decrease at T24h means values have increased or decreased compared to the values during treatment. 

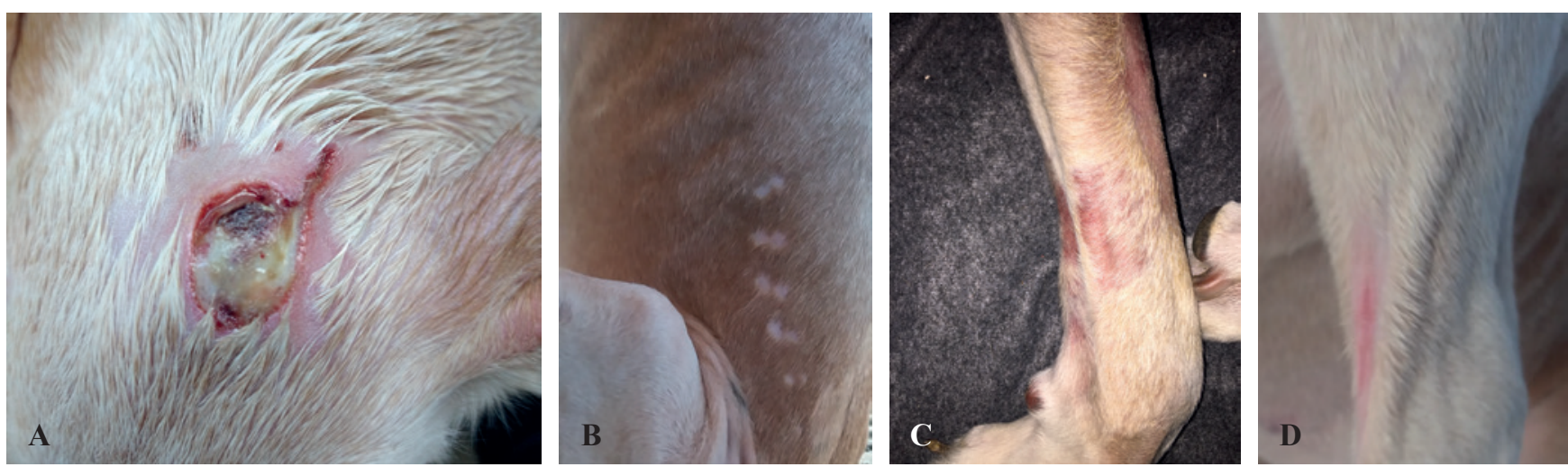

Figure 3. A. Third-degree full-thickness burn wound on the head and B. alopecia and erythema on the flank, C. left forelimb and $D$. at the level of the medial epicondyle of the left humerus.

was allowed to further cool down to a normal body temperature during the night.

At times of reduced urinary output, furosemide (Dimazon ${ }^{\circledR} ; 0.5 \mathrm{mg} \cdot \mathrm{kg}^{-1}$; Intervet International; Unterschleißheim, Germany) was administered IV to revive diuresis. A CRI of Tracrium (Atracrium ${ }^{\circledR} ; 0.2 \mathrm{mg} . \mathrm{kg}$ ${ }^{1} . h^{-1}$; Aspen Pharma Trading Limited; Dublin, Ireland) was administered IV when the patient started to fight the mechanical ventilation and remained ongoing until the end of treatment. The means of anesthetic monitoring were limited, and the anesthetic depth was mainly judged based on heart rate and respiratory rate.

Arterial blood pressure was continuously measured. When low blood pressure was registered, an

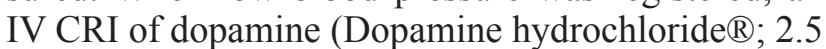
$\mu \mathrm{g} . \mathrm{kg}^{-1} \cdot \mathrm{h}^{-1}$; Laboratório MEDINFAR; Amadora, Portugal) was installed and remained ongoing until the patient was able to maintain its own blood pressure. Every two hours, blood samples were taken for hematology, biochemistry, electrolyte analysis, coagulation status, coagulation factors and blood gases (Table 1).

During the first WBTT, an episode of hypotension was registered (T2h; SAP: $88 \mathrm{mmHg}$; DAP: $42 \mathrm{mmHg}$; MAP: $58 \mathrm{mmHg}$ ) that responded to the Dopamine CRI. The patient was disconnected from all medical devices and recovered uneventfully from the first anesthesia. Because blood pressure measurements with a Doppler probe and inflatable cuff during hospitalization revealed that hypotension was still present (data not shown), the dopamine CRI remained ongoing until the patient was able to maintain its own blood pressure. During the first day of hospitalization (D1), anorexia was noticed. On the third day of hospitalization, edema was noticed, cranio-distal in the right anal sac. The patient was discharged at D3. No other clinically relevant side effects were present until the next scheduled follow-up appointment at D14. At that time, the patient had developed a $2 \mathrm{~cm}$ patch of erythema and alopecia on the head.

The treatment was repeated on D21. A CRI of dopamine $\left(4 \mu \mathrm{g} \cdot \mathrm{kg}^{-1} \cdot \mathrm{h}^{-1}\right)$ was again administered due to an episode of hypotension. After this second WBTT, the patient was tachypneic. The tachypnea disap- peared without additional treatment on the third day of hospitalization (D24).

The third session was postponed for twenty days because of technical issues with the WBTT device. On the first and second day of hospitalization, after the third WBTT treatment (D72 and D73), edema of the left forelimb was noticed. The edema had disappeared on the third day of hospitalization (D74). In addition, numerous areas of alopecia were observed during hospitalization. The follow-up appointment on D86 revealed a full-thickness third-degree burn wound on the head and multiple partial thickness burns on the flank and forelimbs (Figure 3).

The CT scan performed after the last combined treatment session (D86) revealed the right medial iliac lymph node had decreased in length but increased in height $(17.8 \times 20.6 \times 33.4 \mathrm{~mm})$, while the right internal iliac lymph node had decreased in length, width, and height $(38.2 \times 20.3 \times 17.7 \mathrm{~mm})$. The nodule in the right anal sac had also decreased in size $(8.1 \times 5.6$ x $5.6 \mathrm{~mm}$ ). A well-defined hypoattenuating nodule (5 $\mathrm{mm}$ in diameter) in the right medial liver lobe was present and likely degenerative, but a metastatic lesion could not be excluded. A soft tissue attenuating nodule $(8.9 \times 5.0 \mathrm{~mm})$ was visible in the right caudal lung lobe. In the dorsal aspect of the right cranial lung lobe, another ill-defined region $(4 \mathrm{~mm})$ of soft tissue attenuation was present.

Another agreed-upon follow-up appointment was planned two months later for restaging of the anal sac adenocarcinoma and its metastases, after the combined treatment of WBTT and hypofractionated radiotherapy. The $\mathrm{CT}$ scan performed on that day (D148) revealed the nodule in the right anal sac had even further reduced in size $(7.6 \times 3.7 \times 6.0 \mathrm{~mm})$ and was barely distinguishable from the wall of the right anal sac. Both the right medial iliac lymph node (18.0 x $7.9 \times 9.7 \mathrm{~mm}$ ) and right internal iliac lymph node $(14.0 \times 11.0 \times 14.4 \mathrm{~mm})$ had also decreased in size. An increase in size of the left medial iliac lymph node was noticed $(22.0 \times 5.8 \mathrm{~mm})$, which was not present in the previous examinations. The adrenal glands had also increased in size compared to previous examina- 

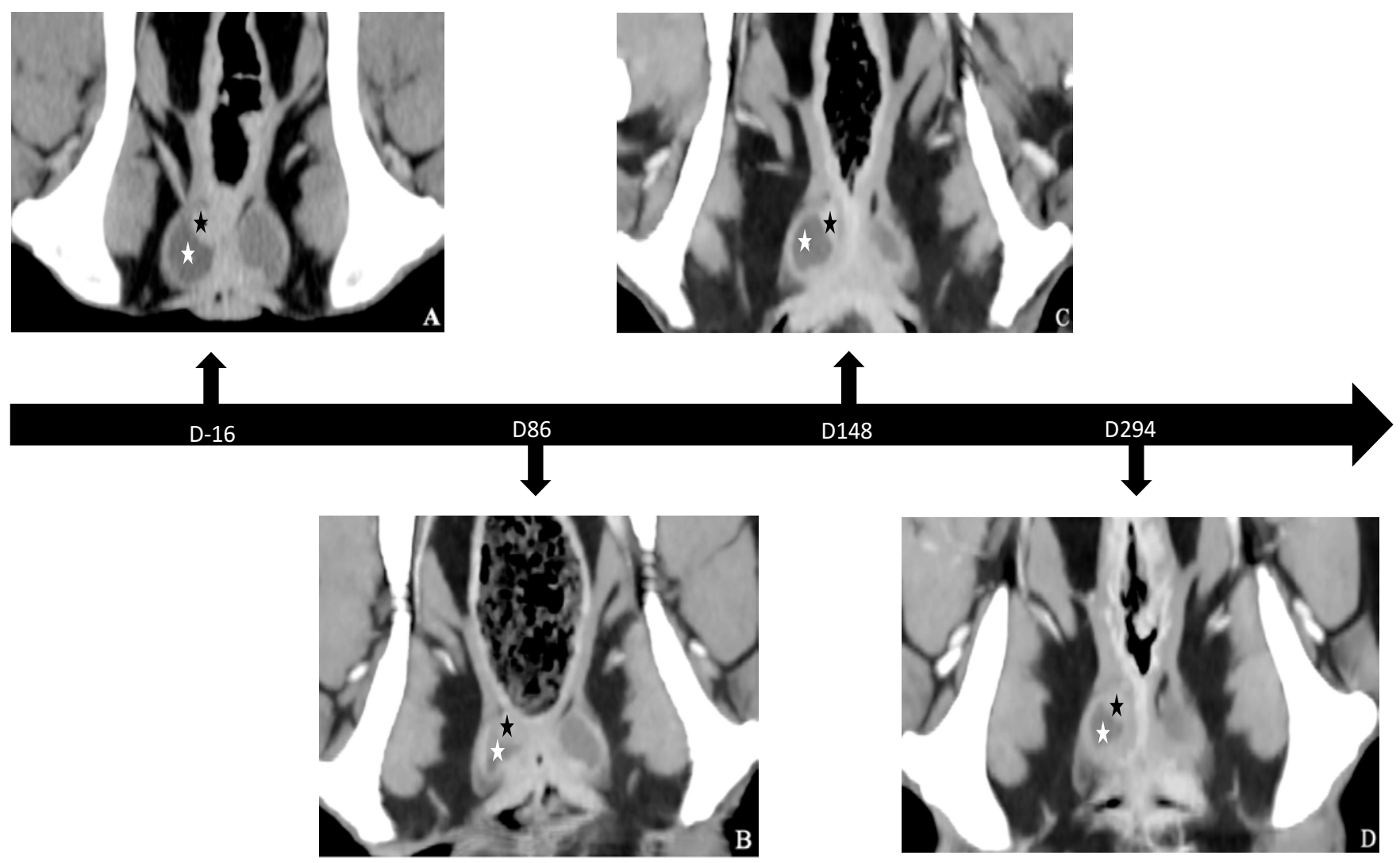

Figure 4. Dorsal reconstruction post contrast CT image in soft tissue algorithm at the level of the anal sacs. An overview on the evolution of the size of the primary tumor at four different time points: D-16 (A), D86 (B), D148 (C), D294 (D). Based on the calculations the nodule had been reduced in size on D86 and D148. A slight increase in size is noticed on D294. White asterisk = anal sac; black asterisk = primary tumor.

tions (left $20 \%$ and right $15.5 \%$ increase in size). Because the pituitary gland height to brain ratio was 0.41 (normal $<0.31$ ), the adrenomegaly was thought to be associated with pituitary-dependent hyperadrenocorticism. However, a low-dose dexamethasone suppression test, a urinary cortisol:creatinine test in combination with a high-dose dexamethasone suppression test and an adrenocorticotropic hormone stimulation test to test for Cushing disease were all negative. The previously described nodule in the right caudal lung lobe had decreased in size $(7.1 \times 3.5 \mathrm{~mm})$ but a few small hyperattenuating nodules of maximum $1 \mathrm{~mm}$ were noticed in the peripheral pulmonary parenchyma. These pulmonary nodules were most likely consistent with benign osseous metaplasia.

The last follow-up appointment for restaging was performed on D294. The CT scan revealed a 76.8\% increase of the nodule in the right anal sac (Figure $4)$. The right internal iliac lymph node had mildly increased in size $(23.0 \times 10.0 \times 15.8 \mathrm{~mm})$. The right medial iliac lymph node had further decreased in size $(11.4 \times 6.3 \times 6.4 \mathrm{~mm})$ (Figure 5). The left medial iliac lymph node had remained approximately the same size as on D148. The appearance of both adrenal glands and the pituitary gland was similar to D148. A hypoattenuating nodule was present in the parenchyma of the right lateral liver lobe $(5.3 \mathrm{~mm}$ in diameter $)$ and the left lateral liver lobe ( $6.4 \mathrm{~mm}$ in diameter) but these nodules were presumed to be either degenerative or due to metabolic hepatopathy.

The QoL was measured during and after each treatment. Throughout and after the combined WBTT and hypofractionated radiotherapy sessions, QoL was good. The physical examination on D294 revealed the same moderate gingivostomatitis and mild regional enlargement of the submandibular and prescapular lymph nodes. Blood pressure was not measured due to a history of white-coat hypertension. On hematology, no clinically relevant deviations were noticed. Breed associated neutropenia remained present. Urinalysis revealed isosthenuria (USG 1.017) with the same pronounced renal proteinuria (UPC 2.6). However, the UPC ratio had been reduced to 1.7 with telmisartan (Telmisartan EG® ${ }^{\circledR} 40 \mathrm{mg}$; Eurogenerics NV; Brussels, Belgium) on D229, but, as diarrhea was noticed and the owners suspected it to be a side effect of the drug, the treatment was stopped and, subsequently, the pronounced renal proteinuria returned. Furthermore, two subcutaneous nodules were observed, one lipoma-suspected cranio-ventrally on the thorax and one hard nodule on the sternum. Cytological examination of these nodules was not diagnostic. The patient was 

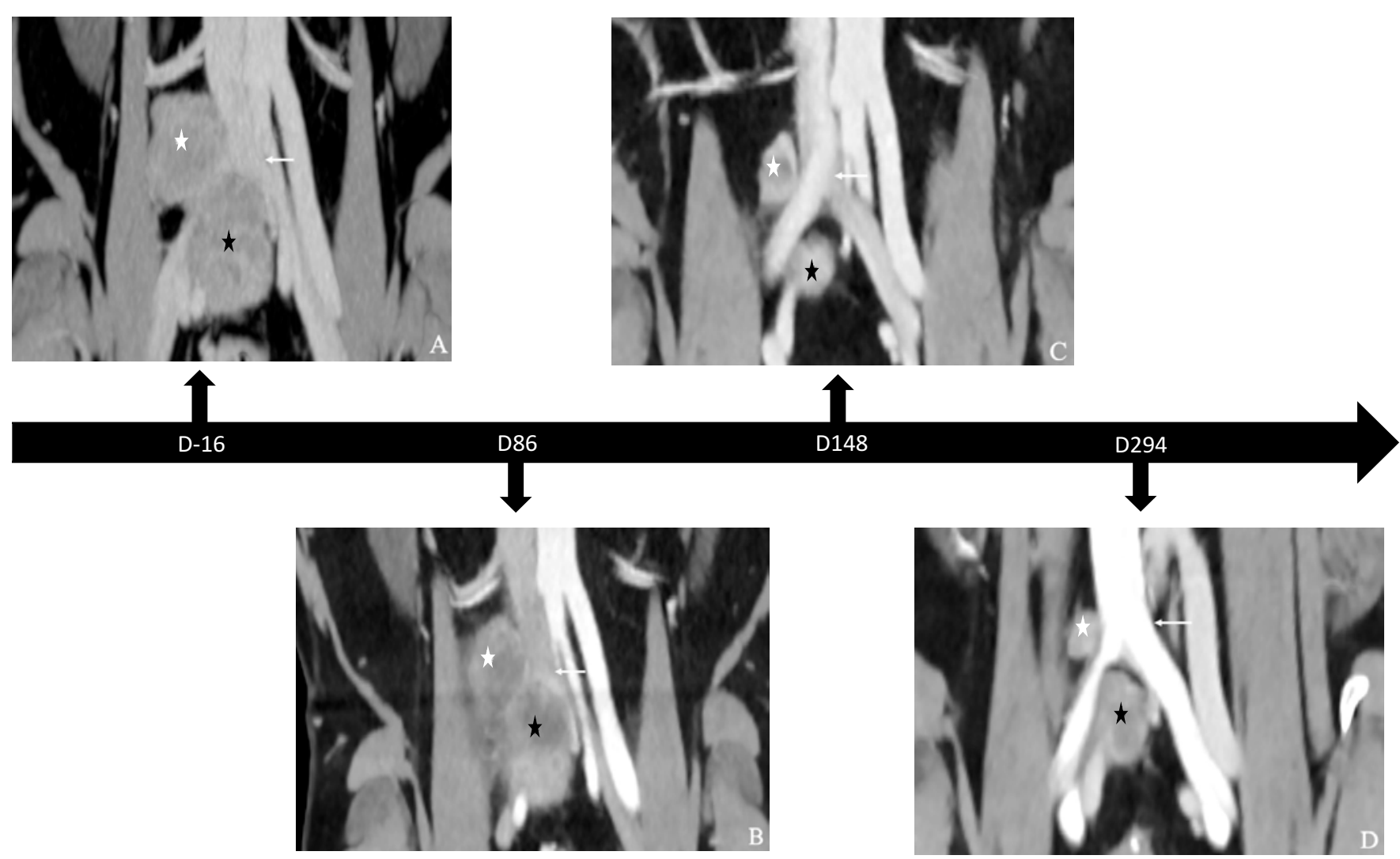

Figure 5. Dorsal reconstruction post contrast CT image in soft tissue algorithm at the level of the caudal abdominal aorta trifurcation. An overview on the evolution of the size of the locoregional metastases at four different time points. The four different time points include D-16 (A), D86 (B), D148 (C) and D294 (D). A reduction in size of the right medial iliac lymph node is visible on D86. On D148, both lymph nodes are clearly reduced in size. On D294, the right medial iliac lymph node decreased even further in size, whereas the right internal iliac lymph node had increased in size again. White arrow $=$ caudal abdominal aorta trifurcation; white asterisk = right medial iliac lymph node; black asterisk $=$ right internal iliac lymph node.

in good health according to the owners. Meloxicam (Metacam ${ }^{\circledR} ; 1.5 \mathrm{mg} / \mathrm{ml} ; 0.1 \mathrm{mg} / \mathrm{kg}$; Boehringer Ingelheim Vetmedica GmbH; Ingelheim, Germany) was started for palliative treatment control and telmisartan was again prescribed.

Due to sudden rapid progressive polyneuropathy, the patient was euthanized on D506. The sudden polyneuropathy might have been linked to the progression of the disease or might have been paraneoplastic. Autopsy was declined by the owners.

\section{DISCUSSION}

Thermal therapy is a medically induced treatment approach, clinically applied to enhance the effectiveness of radiotherapy and chemotherapy in the treatment of primary and recurrent tumors (Oei et al., 2020). In the literature, thermal therapy is most often referred to as hyperthermia. The term hyperthermia refers to the use of heat in the treatment of malignant tumors (Cheng et al., 2019). Medical thermal therapy can be divided into local thermal therapy, regional thermal therapy and WBTT. In addition, subdivisions are made in the range of temperature elevations (Rao et al., 2010; Wehner et al., 2018). In the care of cancer dogs, mild thermal therapy $\left(39-42^{\circ} \mathrm{C}\right)$ is used. This temperature range is also called fever-range thermal therapy (Yagawa et al., 2017).

In case of metastatic disease, only WBTT is considered a plausible hyperthermic method (Oei et al., 2020). Heating methods for WBTT include biological methods, contact methods, extracorporeal perfusion and superficial heating methods (Milligan, 1984; Pang and Lee, 2016). The biological method aims to heat the body by injection of a pyrogenic microbial or biologic agent. This method is rarely applied at present due to unpredictable sensitive reactions and uncontrolled temperature rises and duration (Pang and Lee, 2016). Direct-contact methods aim to transfer heat to the patient by using conduction, convection and/or distribution via circulating blood (Milligan, 1984; Pang and Lee, 2016). Modalities like hot wax baths, heated water blankets surrounding the patient or a space suit have been developed. The space suit offers more surface area available for heat transfer and therefore requires a lower temperature of circulating water, which decreases the risk of burns at pres- 
sure points (Milligan, 1984). However, direct-contact methods are not without risks and therefore have never been popular (Pang and Lee, 2016). Nor are extracorporeal perfusion methods appealing as blood needs to be heated outside the patient, requiring the use of anti-coagulants (Vertrees et al., 2001; Pang and Lee, 2016). There is interest in the use of superficial heating methods, such as infrared radiation heating techniques, due to fewer side effects, ease of monitoring and lower costs (Pang and Lee, 2016).

In this case report, a repeated long-term WBTT (eight hours at $41.5^{\circ} \mathrm{C}$ ) is described in a sophisticated medical treatment cabinet. An experimental medical device, the HyperTherm, and the treatment protocol were developed by ElmediX to deliver controlled and accurate thermal treatment as an adjuvant therapy for oncology patients. The length of therapy was decided upon based on previous preclinical experiments by ElmediX. The sessions were well tolerated, and prolonged severe adverse effects were not observed. In addition, preliminary results of the efficacy were noticed, as the combined treatment sessions with hypofractionated radiotherapy, which aimed at the primary tumor as well as the lymphatic metastases, clearly reduced the size of the anal sac nodule and its lymphatic metastases (Table 2). These results obviously need to be confirmed in a larger population of canine cancer patients.

The described patient was diagnosed with disseminated anal sac adenocarcinoma. Treatment of anal sac adenocarcinoma traditionally consists of surgery in combination with adjuvant chemo- or radiotherapy (Morris and McNaught, 2015), hypofractionated radiotherapy alone (Sivacolundhu, 2016), tyrosine kinase inhibitors (Morris and McNaught, 2015) or nonsteroidal anti-inflammatory drugs (Knudsen et al., 2013). Chemotherapy is often used in case of distant metastases as it targets possible micrometastases (Oei et al., 2020). Radiotherapy is better suited for local macroscopic tumor lesions (Oei et al., 2020). Tyrosine kinase inhibitors and non-steroidal anti-inflammatory drugs are palliative treatment options but can also be of clinical benefit when other therapies have failed or are not desired (Knudsen et al., 2013; Morris and McNaught, 2015). The survival rates with treatment depend on the choice of treatment, the cancer stage and the physiological state of the patient (Morris and McNaught, 2015). In this patient, surgery was considered too complex and invasive due to the pres- ence of the abdominal lymphatic metastases. Chemoand radiotherapy alone were declined because of their possible side effects. However, as the survival rate without any treatment would have been approximately six months (Polton and Brearley, 2007; Meier et al., 2017), the owners decided to enroll their dog in a clinical trial, involving the combination of WBTT and hypofractionated radiotherapy. The combination of WBTT with a low dose of radiotherapy gave the patient a survival in the upper range of what could have been expected in case she would have received a standard of care treatment such as curative-intent surgery or isolated radiotherapy (Meier et al., 2017).

The patient underwent WBTT at $41.5^{\circ} \mathrm{C}$ by circulating air in a dedicated treatment cabinet designed to safely induce, measure and maintain a constant elevated body temperature. The used treatment protocol was proven safe and manageable in Aachen minipigs (Carneiro et al., 2021). Reported beneficial effects of WBTT include enhancement of immunity, inhibition of DNA repair mechanisms and an increase of perfusion to tumors, making them more susceptible to adjuvant radiotherapy (Mallory et al., 2015). The molecular changes involved have been attributed to the upregulation of heat shock proteins (Calderwood et al., 2005; Calderwood, 2007), a defective G1/S checkpoint in tumor cells (Kaur et al., 2011), inhibition of DNA-repair mechanisms (Oei et al., 2015) and dilation of host-incorporated arterioles in tumor vascular beds (Song et al., 2005).

Incorporating this treatment modality into multimodality treatment planning enhances sensitivity of tumor cells to chemo- and radiotherapy, whereas normal tissue cells are protected from damage due to their normal hierarchically assembled vasculature, allowing heat dissipation (Mallory et al., 2015). The temperature dose, temperature duration and time interval between administering WBTT and the second treatment are possible key factors in the anti-cancer effect (Kaur et al., 2011; Oei et al., 2020). Inhibition of DNA repair mechanisms occurs at temperatures above $41^{\circ} \mathrm{C}$, and synergistic effects are optimal in case of simultaneous administration of both heat and ionizing radiation (Oei et al., 2020).

Although long-term effects were not obtained, as eight months after the last combined treatment session the anal sac nodule and lymph nodes had again increased in size, the combined treatment sessions substantially slowed down the progression of the disease.

Table 2. An overview on evolution of growth of the primary tumor as well as its lymphatic metastases at the level of the right medial iliac lymph node and right internal iliac lymph node.

\begin{tabular}{lccc}
\hline Day & Primary tumor & Right medial iliac lymph node & Right internal iliac lymph node \\
\hline D16 & $12.6 \times 6.9 \times 10.5 \mathrm{~mm}$ & $35.6 \times 26.4 \times 22.5 \mathrm{~mm}$ & $38.3 \times 24.7 \times 29.6 \mathrm{~mm}$ \\
D86 & $8.10 \times 5.6 \times 5.6 \mathrm{~mm}$ & $17.8 \times 20.6 \times 33.4 \mathrm{~mm}$ & $38.2 \times 20.3 \times 17.7 \mathrm{~mm}$ \\
D148 & $7.6 \times 3.7 \times 6.0 \mathrm{~mm}$ & $18.0 \times 7.9 \times 9.7 \mathrm{~mm}$ & $14.0 \times 11.0 \times 14.4 \mathrm{~mm}$ \\
D294 & $7.9 \times 5.9 \times 6.4 \mathrm{~mm}$ & $11.4 \times 6.3 \times 6.4 \mathrm{~mm}$ & $23.0 \times 10.0 \times 15.8 \mathrm{~mm}$ \\
\hline
\end{tabular}


Observed adverse effects during and following WBTT included hypotension, tachypnea, anorexia and skin lesions. In human medicine, it has been shown that while WBTT increases the heart rate, a drop in the systemic vascular resistance occurs during WBTT when the body temperature exceeds $40^{\circ} \mathrm{C}$ (Kerner et al., 2002), most likely due to alterations in thermal sensitivity of arterial baroreceptors and/or effects on the central nervous system (Haveman et al., 2004). The dopamine CRI in the dog of the present case successfully counteracted the hypotension. Also tachypnea has previously been reported and has been associated with a drop in PCO2 in dogs under WBTT (Macy et al., 1985). The occurrence of post-treatment anorexia may be explained by changes in splanchnic oxygen levels triggered by a redistribution of blood flow, thermal (in)activation of enzymes (Hall et al., 2001) and alterations in the gut microbiome (Hylander and Repasky, 2019). However, as this patient had always been very nervous at the clinical appointments and during hospitalization, the authors believe that the observed anorexia in this patient was likely also related to stress. The only severe adverse effects in the treated dog were skin lesions: erythema, alopecia, a full-thickness, third-degree burn wound on the head and partial thickness burn wounds on the flank and limbs. These wounds occurred at pressure points. During each treatment session, the patient was positioned in dorsal recumbency. The inciting factor of the reported skin lesions (present after the first WBTT session and worse after the second and third WBTT sessions) is believed to be due to prolonged unrelieved pressure on the skin during treatment, resulting in alterations in skin vascularization. Superficial skin lesions on the head were also noticed in two other dogs undergoing this WBTT $\left(41.5^{\circ} \mathrm{C}, 8\right.$ hours $)$. However, the patient described in this case report was the only patient with this severity of burn wounds. Galgo Espagnols are known to have a very thin skin and a low amount of subcutaneous fat tissue compared to other dog breeds, which may have made her more prone to burn injuries at pressure points. These wounds at pressure points should be counteracted in future trials by the use of special mattresses which provide a softer surface for the patient and a treatment cabinet that is large enough to allow for ideal positioning of the patient. Given the experimental nature of the clinical trial, regular blood analyses were performed. The observed abnormalities in the blood parameters were very temporary in nature and did not seem to be of any clinical relevance in the patient.

Whether the enlargement of the pituitary gland was due to the exposure of heat during treatment or whether it should be seen as an entity with a different cause, is not known. No pre-treatment CT images of the pituitary gland were available, and therefore, no comparison between pre- and post-treatment could be made. However, in five other dogs with disseminated neoplastic disease enrolled in this clinical trial, enlargement of the pituitary gland was not observed.
Necropsy of Aachen minipigs that underwent WBTT for safety evaluation also revealed no abnormalities within the brain (Carneiro et al., 2021). The effect of WBTT on brain tissue in dogs has been reported, both on the effect of brain hemodynamics and the bloodbrain barrier (Katsumura et al., 1995) as well as histological induced changes (Takahashi et al., 1999; Haveman et al., 2005). In several studies, it has been shown that temperatures up to $42^{\circ} \mathrm{C}$ for sixty minutes induce neither microscopic damage to the central nervous system nor central neural dysfunction (Takahashi et al., 1999; Haveman et al., 2005).

HyperTherm-mediated WBTT combined with hypofractionated radiotherapy in the patient of the present case was safe and clinically manageable. Although a positive treatment effect was observed, retardation of tumor growth was only temporarily. Nevertheless, the outcome invites to unravel the biological induced effects and molecular mechanisms involved to further adjust the treatment protocol and obtain longer-lasting effects in combination with increased QoL by limiting the severity of potential side effects observed with conventional treatment strategies such as chemotherapy and radiotherapy.

\section{ACKNOWLEDGEMENT}

The authors want to thank Oncovet Clinical Research (OCR) for the coordination of the study, the set-up of the protocol and for processing the data, and Oncovet Veterinary Cancer Centre for conducting the study.

\section{REFERENCES}

Calderwood, S.K. (2007). Heat shock proteins in extracellular signaling. Methods 43, 167.

Calderwood, S.K., Theriault, J.R., Gong, J. (2005). How is the immune response affected by hyperthermia and heat shock proteins? International Journal of Hyperthermia 21, 713-716.

Carneiro, M.W., Brancato, L., Wylleman, B., van Zwol, E., Conings, L., Vueghs, P., Gorbaslieva, I., Bossche J. Van Den, Rudenko, O., Janicot, M., Bogers, J. (2021). Safety evaluation of long-term temperature controlled wholebody thermal treatment in female Aachen minipig. International Journal of Hyperthermia 38, 165-175.

Cheng, Y., Weng, S., Yu, L., Zhu, N., Yang, M., Yuan, Y. (2019). The role of hyperthermia in the multidisciplinary treatment of malignant tumors. Integrative Cancer Therapies $18,1$.

Cui, X-W., Jenssen, C., Saftoiu, A., Ignee, A., Dietrich, C.F. (2013). New ultrasound techniques for lymph node evaluation. World Journal of Gastroenterology 19, 4853.

Hall, D.M., Buettner, G.R., Oberley, L.W., Xu, L., Matthes, R.D., Gisolfi, C.v. (2001). Mechanisms of circulatory and intestinal barrier dysfunction during whole body hyperthermia. American Journal of Physiology - Heart and Circulatory Physiology 280, 509-521. 
Haveman, J., Sminia, P., Wondergem, J., van der Zee, J., Hulshof, M. C. C. M. (2005). Effects of hyperthermia on the central nervous system: What was learnt from animal studies? International Journal of Hyperthermia 21, 473-487.

Haveman, J., Van der Zee, J., Wondergem J., Hoogeveen, J.F., Hulshof, M.C.C.M. (2004). Effects of hyperthermia on the peripheral nervous system: A review. International Journal of Hyperthermia 20, 371-391.

Hylander, B.L., Repasky, E.A. (2019). Temperature as a modulator of the gut microbiome: what are the implications and opportunities for thermal medicine? International Journal of Hyperthermia 36, 83-89.

Katsumura, H., Kabuto, M., Hosotani, K., Handa, Y., Kobayashi, H., Kubota, T. (1995). The influence of total body hyperthermia on brain haemodynamics and bloodbrain barrier in dogs. Acta Neurochirurgica 135, 62-69.

Kaur, P., Hurwitz, M.D., Krishnan, S., Asea, A. (2011). Combined hyperthermia and radiotherapy for the treatment of cancer. Cancers 3, 3799-3823.

Kerner, T., Desja, M., Ahlers, O., Hildebrandt, B., Dieing, A., Riess, H., Wust, P., Gerlach, H. (2002). Monitoring arterial blood pressure during whole body hyperthermia. Acta Anaesthesiologica Scandinavica 46, 561-566.

Knudsen, C.S., Williams, A., Brearley, M.J., Demetriou, J.L. (2013). COX-2 expression in canine anal sac adenocarcinomas and in non-neoplastic canine anal sacs. Veterinary Journal 197, 782-787.

Macy, D.W., Macy, C.A., Scott, R.J., Gilette, E.J., Speer, J.F. (1985). Physiological Studies of Whole-Body Hyperthermia of Dogs. Cancer Research Journal 45, 2769-2773.

Mallory, M., Gogineni, E., Jones, G.C., Greer, L., Simone II, C.B. (2016). Therapeutic hyperthermia: The old, the new, and the upcoming. Critical Reviews in Oncology/ Hematology 97, 56-64.

Meier, V., Polton, G., Cancedda, S., Roos, M., Laganga, P., Emmerson, T., Bley, C.R. (2017).

Outcome in dogs with advanced (stage $3 \mathrm{~b}$ ) anal sac gland carcinoma treated with surgery or hypofractionated radiation therapy. Veterinary and Comparative Oncology 15, 1073-1086.

Milligan, A.J. (1984). Whole body hyperthermia induction techniques. Cancer Research 44, 4869-4872.

Morris, J., McNaught, K. (2015). Anal sac adenocarcinoma; a hidden cancer. International Animal Health Journal 43, 38-43.

Oei, A.I., Kok, H.P., Oei, S.B., Horsman, M.R., Stalpers, L.J.A., Franken, N.A.P., Crezee, J. (2020). Molecular and biological rationale of hyperthermia as radio- and chemosensitizer. Advanced Drug Delivery Reviews 163-164, 84-97.
Oei, A.L., Vriend, L.E.M., Crezee, J., Franken, N.A.P., Krawczyk, P.M. (2015). Effects of hyperthermia on DNA repair pathways: One treatment to inhibit them all. Radiation Oncology 10, 1-13.

Pang, C.L.K. (2016). Whole-body hyperthermia. In: Lee, K. (editor). Hyperthermia in Oncology. First edition, CRC Press, Boca Raton, p. 113.

Polton, G. A., Brearley, M. J. (2007). Clinical stage, therapy, and prognosis in canine anal sac gland carcinoma. Journal of Veterinary Internal Medicine 21, 274-280.

Rao, W., Deng, Z-S., Liu, J. (2010). A review of hyperthermia combined with radiotherapy/chemotherapy on malignant tumors. Critical Reviews in Biomedical Engineering 38, 109.

Sivacolundhu, R.K. (2016). Anal sac adenocarcinoma in dogs. World Small Animal Veterinary Association Congress Proceedings. URL: https://ap.lc/5MuK0

Song, C.W., Park, H.J., Lee, C.K., Griffin, R. (2005). Implications of increased tumor blood flow and oxygenation caused by mild temperature hyperthermia in tumor treatment. International Journal of Hyperthermia 21, 764.

Takahashi, S., Tanaka, R., Watanabe, M., Takahashi, H., Kakinuma, K., Suda, T., Yamada, M., Takahashi, H. (1999). Effects of whole-body hyperthermia on the canine central nervous system. International Journal of Hyperthermia 15, 203-216.

Vertrees, R.A., Zwischenberger, J.B., Woodson, L.C., Bedell, E.A., Deyo, D.J., Chernin, J.M. (2001). Veno-venous perfusion-induced systemic hyperthermia: case report with perfusion considerations. Perfusion 16, 243-248.

Wehner, H., Wey, S., Meyer, A. (2018). Whole body hyperthermia guideline. Deutsche Gesellschaft für Hyperthermie e.V. First edition. URL: https://ap.lc/RoJB9

Wylleman, B., Brancato, L., Gorbaslieva, I., van Zwol, E., Mori da Cunha, M.G.M.C., Benoit, J., Vueghs, P., Van den Bossche, J., Rudenko, O., Janicot, M., Bogers, J. (2021). Tolerability of long-term temperature controlled wholebody thermal treatment in advanced cancer-bearing dogs. International Journal of Hyperthermia. Manuscript under review.

Yagawa, Y., Tanigawa, K., Kobayashi, Y., Yamamoto, M. (2017). Cancer immunity and therapy using hyperthermia with immunotherapy, radiotherapy, chemotherapy and surgery. Journal of Cancer Metastasis Treatment 3, 219.

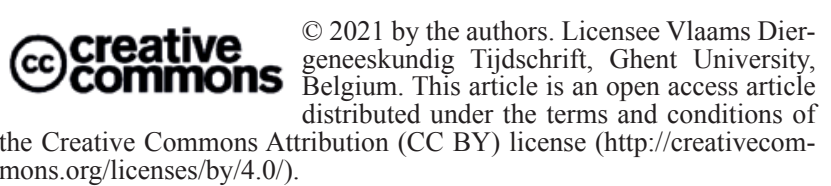

